\title{
COMPARISON OF COMPETITIVENESS OF GRID COMPANIES AND INDUSTRIAL COMPANIES' OWN GENERATING UNITS
}

\author{
L.M. GITELMAN ${ }^{1}$, L.D. GITELMAN ${ }^{1}$ \& A.V. DENISOV ${ }^{2}$ \\ ${ }^{1}$ Department of Energy and Industrial Management Systems, Ural Federal University, Russia. \\ ${ }^{2}$ Branch of JSC "Interregional Distribution Grid Company of Ural" -"Chelyabenergo", Russia.
}

\begin{abstract}
In contemporary Russia, the existing electricity supply model is gradually changing, the focus shifting to the priority development of small-scale distributed power generation. It is, however, impossible to significantly reduce grid electricity consumption in the near future. Conditions for grid companies are getting increasingly competitive, which may result in higher tariffs for consumers. At the same time, the development of small-scale power generation in this country is chaotic and its efficiency has never been adequately compared to that of grid electricity consumption.

The article looks at factors and conditions that may help boost grid companies' competitiveness. It also provides a new developed methodology for comparative analysis of the efficiency of the construction of a company's own generating unit as opposed to consuming grid electricity. The article contains estimates of the cost of connection technologies to the grid and electricity tariffs for different scenarios of development. The article looks at the potential for tariff reduction and reveals peculiarities and the cost of construction and operation of generating units for industrial companies. The methodology was tested in Chelyabinsk Region which is served by JSC "Interregional Distribution Grid Company of Ural".

Keywords: comparative efficiency of small-scale power generation projects and grid electricity, competitiveness of power grid, cost of electricity production, development of small-scale and distributed power generation, electricity tariffs.
\end{abstract}

\section{INTRODUCTION}

Nowadays some industrial companies are trying to come up with an alternative for centralized electricity supply as their demand for electricity is not being met effectively due to significant power losses and steady growth of electricity and heating tariffs. As a result, a lot of small-scale generating units are being built. Meanwhile, a number of problems relating to cross-subsidization, lack of incentives for investment, reliability of electricity supply and high connection tariffs have not been solved on the national level yet. That hampers the development of the progressive trend, as indicated by the experience of developed countries $[1,2]$.

For example, in the EU distributed power generation accounts for an average of $10 \%$ of total electricity production (45\% in Denmark). In the USA some 12 million small-scale distributed generation units are operating, with a unit capacity of up to $60 \mathrm{MW}$ and overall installed capacity of over $220 \mathrm{GW}$. Moreover, it tends to grow at a rate of about $5 \mathrm{GW}$ a year [3-5].

It is noteworthy that the development of small-scale distributed generation (generating units with the capacity between $1 \mathrm{MW}$ to $50 \mathrm{MW}$ located in close proximity to the consumer 
where energy storage systems and Smart Grid technologies can be used) has become a priority in Russia.

The above-mentioned trend may have a positive effect on the Unified Energy System of Russia, too as it will make it possible to solve a number of problems, such as:

1. No need to construct excess generating capacity (accompanying grid infrastructure), including projects with public financing.

2. More flexible regulation of load in the grid.

3. Partial offset of grid losses.

4. Provision of electricity supply in isolated energy areas.

At the beginning of 2015 the total installed electric capacity of all distributed generation facilities in the Russian Federation made up some 8 to $9 \mathrm{GW}$, with 6 to $6,5 \mathrm{GW}$ being in operation. Distributed power generation tends to steadily grow by 500-600 MW a year [6].

However, the development of small-scale power generation in Russia will remain gradual, especially under the current economic conditions. It is essential to offer an unbiased assessment of all advantages and disadvantages of this task.

Equipment manufacturers and suppliers have their own reasons to recommend the introduction of small-scale power generation:

- Companies' own generating units ensure energy independence.

- The energy market is unstable and electricity prices will keep growing.

- Electricity tariffs are not economically justified.

- The cost of electricity production by a company's own generating unit will be two times lower than the price of grid electricity.

- Payback period for a company's own generating unit ranges between two to five years.

- Reliability of the latest generators is comparable to that of grid electricity consumption $[7,8]$.

In view of the above-mentioned one can infer that the small-scale power generation market will grow every year while the risks of major electricity producers and grid companies will increase $[9,10]$.

Electricity transmission volumes will decrease as consumers who install their own generating units will use less grid electricity. However, they will remain connected to the grid to ensure reliability so semi-fixed costs will still be paid. Expenditures will grow due to the technological connection of the low-voltage domestic load with high per-unit costs which are not offset by an increase in the volumes of the services provided.

Thus, backbone energy companies as well as grid companies are faced with a challenge of improving their competitiveness against small-scale power generation.

\section{RESEARCH METHODOLOGY}

Due to state regulation of electricity tariff competition between grid companies and smallscale power generation has certain peculiarities. At present power consumers can be either connected to the grid, or not. The main factors which influence consumers' decision to build their own power units are outlined in Table 1. 
Table 1: Factors influencing the decision whether to install a company's own generating unit.

\begin{tabular}{lll}
\hline Factors & $\begin{array}{l}\text { Consumer not connected } \\
\text { to the grid }\end{array}$ & $\begin{array}{l}\text { Consumer connected } \\
\text { to the grid }\end{array}$ \\
\hline Waiting time for grid connection & + & - \\
Cost of grid connection & + & - \\
Cost of $1 \mathrm{kWh}$ of consumed electricity & + & + \\
\hline
\end{tabular}

These are the factors that require a thorough study. In the long run, everything is determined by the amount of investment the consumer is prepared to make during the installation of their own generating unit or pay for grid electricity. That is why we will assess the costs incurred by consumers because of the above-mentioned factors. Moreover, we recommend that the analysis be carried out in the following sequence.

1. Choosing equipment type for small-scale power generation.

At present small-scale power generation in Russia and worldwide features the following generating units:

- Gas turbine.

- Diesel.

- Gas engine.

- Small-scale hybrid systems.

- Small-scale nuclear systems.

- Small-scale power stations using renewable energy sources (solar and wind energy, small-scale hydropower and geothermal energy systems, fuel cells, marine energy, biomass energy, heat pumps).

Gas turbine, diesel and gas engine power plants are the most widespread in Russia. However, because of diesel fuel prices the cost of electricity produced by a diesel power plant is two or three times higher than the cost of grid electricity. Gas engine power plants are the best option for the capacity of up to 5 to $10 \mathrm{MW}$ and small demand for heat energy.

2. Assessing cost of electricity produced at a gas-fuelled power plant.

The following components of the cost need to be analyzed:

- Purchase price of gas.

- Engine oil waste and replacement and other expendable materials.

- Routine maintenance and repair works, including the cost of spare parts.

- Salaries of operating personnel.

- Property tax.

- Depreciation.

When buying a gas engine power plant one should keep in mind that it is virtually impossible to ensure overall support service of the plant by in-house staff. As a rule, after the equipment is bought the in-house staff is taught to carry out such simple operations as the replacement of oil, filters and spark-plugs. But a specialized contractor continues to provide skill-intensive maintenance works not only because they require high qualifications, but also because the works require expensive professional tools which may cost several million roubles. 
Consequently, only companies specializing in regular maintenance and servicing of gas engine power plants can afford them. If the customer's own staff carries out simple service works, it really helps to reduce costs, but the baseline assessment should be made for the toughest framework conditions.

3. Estimating the cost of grid electricity.

The ceiling for non-regulated consumer prices to be paid by organizations is determined on the basis of the price category the consumer belongs to, but in general, the cost of electricity consists of the following structural components:

- Purchase price of electricity in the wholesale and (or) retail market (costs of electricity production at power stations of the wholesale and retail market).

- Transmission tariff.

- Retail markup of the default supplier or utility (expenditures for power supply operation).

- Payment for the services of the following companies: JSC "System Operator of the Unified Energy System" (JSC "SO of UES") for operational and dispatch administration in the power energy sector, JSC "Trading System Administrator" (JSC “TSA") for organization of wholesale trade in electricity, capacity and other goods and services provided by the commercial operator of the wholesale market to the default supplier, CJSC "Financial Settlements Centre" (CJSC "FSC") for calculation of claims and liabilities of wholesale market participants.

4. Analyzing costs of small-scale power generation arrangements versus technological connection to the grid.

When making a decision whether to set up small-scale power generation, for example, for a new facility, the consumer considers not only the cost of electricity production but also the amount of investment required to ensure power supply to the company.

Analysis and comparison of costs for a consumer is carried out for the following variants of energy supply to a new facility:

- Technological connection of the new facility to the grid.

- Stand-alone power supply of the new facility (without connection to the grid) using the company's own power source - a gas engine power plant.

According to dealers' proposals, design and construction time for a gas engine power plant is between 12 to 18 months at the most, which is less than wait time required for technological connection to the grid. One should, however, keep it in mind, that analysis of gas price dynamics is essential as the operation of a gas engine power plant requires connection to the gas network.

5. Estimating the efficiency of the project of installation of a company's own generating unit versus grid electricity consumption.

We shall perform the assessment of efficiency of installation of a gas engine power plant (hereinafter referred to as GEPP) based on evaluation methods for return on investment. The authors recommend using a scenario approach, with several base scenarios forming the methodical framework for the assessment.

1. Connection to high voltage or medium voltage networks.

2. Full use of heat energy ( $100 \%$ heat recovery) or electricity generation only.

3. Operation in parallel with the electric grid or electricity production by a GEPP in island mode. 
4. The grid electricity tariff is at the present level, or the grid electricity tariff is reduced due to a number of measures.

5. Adjustment of the grid electricity tariff at a rate of $7.5 \%$ a year (the existing trend) or the adjustment of the tariff is minimal, $2 \%$ (low rate of tariff indexation).

6. Gas price indexation at a rate of $3 \%$ a year or indexation at a higher rate.

Calculation methodology is based on the following principles:

- The comparison of variants is based on the methods of net present value (NPV) and discounted payback period. Each scenario contains the assessment of capital investments in the construction of a GEPP, the costs getting connected to the grid, the cost of electricity consumed from the grid, and the cost of electricity produced by the generator.

- Cash flow forecast is made for a period of 10 years.

- Cash flows during the first year of the project implementation are capital investment in the construction of a GEPP.

- Cash flows in subsequent years are defined as the difference between expenditures for the purchase of grid electricity, and expenditures for the consumption of electricity produced by a GEPP.

- For variants that envisage electricity consumption both from the grid and from a GEPP, cash flow calculation takes into account the partial purchase of electricity at grid tariffs.

- For a variant of stand-alone power supply from a GEPP the cost of electricity is calculated by multiplying all components of the cost of electricity production by 2 , except for expenditures for buying gas (gas engine power plants work simultaneously to cover the peak load $-2 \mathrm{MW}$ ). The expenditures for buying gas are increased by $10 \%$ due to a drop in efficiency of a GEPP under 50- percent load.

- Reduction factors obtained as a result of generalization and analysis of measures aimed at the reduction of grid electricity tariffs are used for variants with a lowered grid electricity tariff.

\section{TESTING THE METHODOLOGY}

The analysis carried out in compliance with the methodology has yielded the following results.

Time required for connection to the grid and time necessary for the installation of a company's own generating unit are commensurable and depends mostly on the location of facilities that electricity will be supplied to. At the same time, the construction of a company's own generating unit may take longer than connection to the grid as it will require connection to a gas source and available gas amounts in the area. That is why industrial companies tend to use grid electricity along with constructing their own generating units.

It can therefore be affirmed that the time required for the connection to the grid is not the main factor influencing the development of small-scale power generation. The research shows that the opportunity to reduce the cost of electricity and heat tends to determine the decision as to whether a company's own generating unit will be set up.

Our research showed that when making a decision on the construction of a generating unit consumers should consider the following:

- For operation in island mode an additional backup unit should be installed as the main unit will be taken out of service for repair and maintenance. 
- Only operation under a load of at least $50 \%$, both for small-scale power generation and grid electricity consumption, will be efficient. If not, either the efficiency of the generator, or the unit's operational life will decrease.

Estimated investment volumes required for power provision of an industrial company with the capacity of $1,000 \mathrm{KW}$ are presented in Table 2 .

The table shows that the installation of an on-site generating unit requires significant investment, which is five or six times higher than the cost of grid connection. Therefore, given the time required for connection to the gas distribution network and the time required for the construction of a company's own power plant, small-scale power generation cannot be considered an absolute alternative to grid connection. Moreover, for autonomous power supply in island mode the company should also install a stand-by unit, which increases costs almost twofold.

At the same time, for consumers who are already connected to the grid and the gas network the installation of their own generating units may be efficient from the point of view of reducing the cost of electricity.

The growth of electricity production by small-scale power generation will reduce profits from electricity transmission. To improve their competitiveness grid companies need special solutions to reduce the cost of transmitted electricity and introduce new technological solutions attractive to consumers.

In Russia, transmission costs account for some $40 \%$ of the final electricity price (transmission tariff) which is similar to the relevant figures in developed countries [11]. The Federal Antimonopoly Service (FAS) set the threshold for electricity tariff growth at 7.5\% for 2016. Therefore, the reduction of expenses by the grid may help lower the tariff and encourage companies to give up small-scale power generation. Assessing the potential for cutting the costs of a grid company requires a detailed analysis of all components, including expenses of other participants in the electricity transmission market. We suggest looking at the main components comprising these expenses: the cost of grid connection and the cost of consumed electricity.

A. Charges for technological connection to the grid can be calculated in two ways at the consumer's discretion:

- Rate per unit of maximum capacity.

- Standardized rates (for volume of work).

Table 2: Investment, millions of roubles.

\begin{tabular}{|c|c|c|c|}
\hline \multirow[b]{2}{*}{ Investment } & \multicolumn{3}{|c|}{ Options } \\
\hline & $\begin{array}{l}\text { Stand-alone power } \\
\text { supply in island mode }\end{array}$ & $\begin{array}{l}\text { Parallel operation } \\
\text { with grid }\end{array}$ & $\begin{array}{l}\text { Grid electricity } \\
\text { supply }\end{array}$ \\
\hline Connection to the grid & 0 & 9.998 & 9.998 \\
\hline Connection to gas network & 2.160 & 2.160 & 0 \\
\hline $\begin{array}{l}\text { Construction of a gas } \\
\text { engine power plant }\end{array}$ & 50 & 50,0 & 0 \\
\hline Total & 52.160 & 62.158 & 9.998 \\
\hline
\end{tabular}


If there is no technical capacity for technological connection of power receivers a customized engineering design solution is required and in this case a regional tariff regulation body sets a rate for technological connection for this particular consumer.

We calculated the cost of technological connection of a power consumer to the grid for the following baseline parameters:

- Maximum capacity - 1,000 KW.

- Voltage $-10 \mathrm{kV}$.

- Distance to the main substation (Substation 110/10 kV) - $1 \mathrm{~km}$.

- Connection via two cables of $10 \mathrm{kV}$ or a dual circuit overhead transmission line.

- Installation of two transformers of $630 \mathrm{kVA}$ each in a module-type transformer substation (concrete or sandwich panels). Under maximum capacity operation the transformers' load will be $85 \%$.

The estimated payment for technological connection under the above parameters is featured in Table 3.

As technological connection rules provide consumers with an opportunity to choose the way to determine the cost of connection let us assume that the cost of connection of our facility to the grid is 9.998 million roubles.

B. The analysis showed that cutting the budget of grid companies' investment programs of their optimization may help reduce electricity transmission tariffs (unified boiler tariffs). However, it can be done only within certain limits, due to minimization of costs for each project in the first place. The companies should therefore seek opportunities for tariff reduction in all directions: reduction of costs during electricity transmission, reduction of costs of wholesale generating companies, legislative solutions aimed at optimization of price formation in the electric power industry. Here we should notice that "boiler tariff" for electricity transmission services implies the existence of a unified tariff in a region consisting of costs of all grid organizations in the region.

The authors' research shows that the JSC “Interregional Distribution Grid Company of Ural" has potential for reducing its costs (in view of the reduction of payments for the services of other grid organizations and the cost of electricity that has to be bought to compensate for transmission losses) and consequently, the electricity transmission tariff in the near future by $13 \%$ at the most. The boiler tariff accounts for $35 \%$ of the final cost of electricity so if the JSC "Interregional Distribution Grid Company of Ural" reduces spending, it will be able to reduce the final cost of electricity for consumers only by $4.6 \%(0.13 * 35 \%=4.6 \%)$.

As of 2017, consumers will be legally required to pay for reserved maximum capacity. The decision is primarily aimed at reducing reserves that grid companies have to maintain. Nowadays after putting their own generating units into operation some consumers stop paying for transmission services as electricity supply from the grid either drops or stops altogether. But grid companies have to properly maintain grid facilities as those companies still use grid electricity when their generating units are serviced and repaired, or during peak hours.

Table 3: Payment for technological connection, millions of roubles.

\begin{tabular}{lll}
\hline Variants of rates & Connection via cable line & Connection via overhead line \\
\hline Per unit of maximum capacity & 14.500 & 19.549 \\
Standardized rates & 12.012 & 9.998 \\
\hline
\end{tabular}


Some suggest that distributed power generation should be set up in areas with an electricity supply gap. It will help reduce spending on grid overhaul and bridle the growth of tariffs for electricity transmission.

The analysis showed that if the costs incurred by generating companies are reduced by at least percent (changes in natural gas and coal prices are not taken into account) it will make it possible to lower the weighted-average non-regulated price for electricity by $2.9 \%$.

The comparison of electricity consumption from the grid with that an on-site generating unit can be found in Table 4 . The calculation is based on the following baseline parameters:

Table 4: Projects' payback period, years.

\begin{tabular}{|c|c|c|c|c|}
\hline \multirow[b]{2}{*}{ Scenario variants } & \multicolumn{2}{|c|}{ High voltage } & \multicolumn{2}{|c|}{ Medium voltage } \\
\hline & $\begin{array}{l}\text { With heat } \\
\text { recovery }\end{array}$ & $\begin{array}{l}\text { Without heat } \\
\text { recovery }\end{array}$ & $\begin{array}{l}\text { With heat } \\
\text { recovery }\end{array}$ & $\begin{array}{l}\text { Without heat } \\
\text { recovery }\end{array}$ \\
\hline $\begin{array}{l}60 \% \text { GEPP consumption, } 40 \% \text { grid } \\
\text { consumption, current grid tariff, } 3 \% \\
\text { growth of gas tariff }\end{array}$ & 3.1 & 3.9 & 2.2 & 2.6 \\
\hline $\begin{array}{l}60 \% \text { GEPP consumption, } 40 \% \text { grid } \\
\text { consumption, grid tariff reduced, } \\
3 \% \text { growth of gas tariff }\end{array}$ & 3.9 & 5.3 & 3.0 & 3.8 \\
\hline $\begin{array}{l}60 \% \text { GEPP consumption, } 40 \% \text { grid } \\
\text { consumption, grid tariff reduced and low } \\
\text { indexation rate, } 3 \% \text { growth of gas tariff }\end{array}$ & 4.7 & 7.9 & 3.3 & 4.5 \\
\hline $\begin{array}{l}60 \% \text { GEPP consumption, } 40 \% \text { grid } \\
\text { consumption, current grid tariff, } \\
10 \% \text { growth of gas tariff }\end{array}$ & 3.2 & 4.4 & 2.2 & 2.7 \\
\hline $\begin{array}{l}60 \% \text { GEPP consumption, } 40 \% \text { grid } \\
\text { consumption, grid tariff reduced, } \\
10 \% \text { growth of gas tariff }\end{array}$ & 4.3 & 7.0 & 3.1 & 4.2 \\
\hline $\begin{array}{l}60 \% \text { GEPP consumption, } 40 \% \text { grid } \\
\text { consumption, grid tariff reduced and low } \\
\text { indexation rate, } 10 \% \text { growth of gas tariff }\end{array}$ & 5.8 & $\begin{array}{l}\text { does not pay } \\
\text { back }\end{array}$ & 3.5 & 6.5 \\
\hline $\begin{array}{l}100 \% \text { GEPP consumption, } 3 \% \text { growth of } \\
\text { gas tariff, current grid tariff }\end{array}$ & 5.4 & 7.1 & 3.5 & 4.3 \\
\hline $\begin{array}{l}100 \% \text { GEPP consumption, } 3 \% \text { growth of } \\
\text { gas tariff, grid tariff reduced by } 15 \%\end{array}$ & 7.4 & $\begin{array}{l}\text { does not pay } \\
\text { back }\end{array}$ & 5.2 & 6.9 \\
\hline $\begin{array}{l}100 \% \text { GEPP consumption, } 3 \% \text { growth of } \\
\text { gas tariff, grid tariff reduced and low } \\
\text { indexation rate }\end{array}$ & $\begin{array}{l}\text { does not } \\
\text { pay back }\end{array}$ & $\begin{array}{l}\text { does not pay } \\
\text { back }\end{array}$ & 7.5 & $\begin{array}{l}\text { does not } \\
\text { pay back }\end{array}$ \\
\hline $\begin{array}{l}100 \% \text { GEPP consumption, } 10 \% \text { growth of } \\
\text { gas, tariff, current grid tariff }\end{array}$ & 7.1 & $\begin{array}{l}\text { does not pay } \\
\text { back }\end{array}$ & 3.8 & 5.2 \\
\hline $\begin{array}{l}100 \% \text { GEPP consumption, } 10 \% \text { growth of } \\
\text { gas tariff, grid tariff reduced by } 15 \%\end{array}$ & $\begin{array}{l}\text { does not } \\
\text { pay back }\end{array}$ & $\begin{array}{l}\text { does not pay } \\
\text { back }\end{array}$ & 6.7 & $\begin{array}{l}\text { does not } \\
\text { pay back }\end{array}$ \\
\hline $\begin{array}{l}100 \% \text { GEPP consumption, } 10 \% \text { growth } \\
\text { of gas tariff, grid tariff reduced and low } \\
\text { indexation rate }\end{array}$ & $\begin{array}{l}\text { does not } \\
\text { pay back }\end{array}$ & $\begin{array}{l}\text { does not pay } \\
\text { back }\end{array}$ & $\begin{array}{l}\text { does not } \\
\text { pay back }\end{array}$ & $\begin{array}{l}\text { does not } \\
\text { pay back }\end{array}$ \\
\hline
\end{tabular}


- Maximum consumption - $2 \mathrm{MW}$, minimum - $1 \mathrm{MW}$.

- Time of maximum capacity utilization $-50 \%$.

- Capital investment: 50 million roubles for parallel operation of a GEPP with the grid and 100 million roubles for operation in island mode (two gas engine power plants to ensure steady electricity supply during scheduled and unscheduled shutdowns of the main unit).

- Main unit operation hours - 8.000 hours per year.

- Cost of grid electricity in January 2015 - 3.419 roubles per kilowatt-hour (for high voltage) and 4.303 roubles per kilowatt-hour (for medium voltage).

- Natural gas makes up $87 \%$ in the total cost of electricity produced at the GEPP.

- Discount rate $-10 \%$.

We estimated the NPV and discounted payback period for various scenario variants. Since the results are identical for both efficiency indicators, we will analyze results for the second indicator (Table 4).

The analysis of the variants shows that:

- With the existing electricity and gas tariffs in place grid companies cannot compete with companies' generating units, especially if consumers utilize heat recovery.

- Projects relating to the installation of companies' own generating units in parallel mode with the grid when the grid carries exclusively the peak load with invariable tariffs entail most risks for grid companies.

- Reduction of grid electricity tariffs significantly enhances the competitive edge of grid companies versus distributed power generation.

- Competitiveness of grid companies can be ensured in case of parallel operation with small-scale power generation for high-voltage major consumers $(110 \mathrm{kV})$ on the condition of keeping tariffs down.

- When a company installs its own generating facility, it has smaller cash flows within several years which affects the company's capitalization. Moreover, the company that is willing to set up its own generating unit is most likely to need a loan given the amount of initial investment required. That increases financial risks for the company. This factor is not crucial for big companies but for small and medium-sized businesses it will significantly affect the decision as to whether to set up their own generating units especially given high interest rates at the moment.

\section{CONCLUSION}

1. The conducted analysis revealed that at present small-scale power generation may compete with grid organizations if companies' own generating units operate in parallel mode with the grid, and, in some cases, even in island mode. Consumers may significantly reduce expenditures for energy resources due to a lower cost of electricity production by their own generating units.

2. Unbridled development of companies' own generating facilities may negatively affect the economic condition of grid organizations and other participants in the wholesale and retail electricity markets as well as end consumers.

3. Small-scale power generation should undoubtedly develop, but it cannot solve all the problems relating to power supply in the country. Unbridled development of small-scale power generation will cause problems in the power grid, result in the reduction of net electricity supply and significant growth of electricity tariffs. At the same time grid com- 
panies should focus on the prompt introduction of up-to-date technologies in coordination with consumers to better meet their demands [12].

4. To boost their competitiveness grid companies should do the following:

- It is essential for grid organizations to pursue the policy of cutting costs and increasing efficiency, by means of reducing losses in the first place, optimization of other costs, more efficient use of funds earmarked for investment programmes or even suspending and postponing some costly projects. In total, the cost of electricity may drop by $4-5 \%$.

- It is essential for all participants in the wholesale electricity market to reduce costs and boost efficiency of production and investment. That will enable them to partially reduce spending on purchasing electricity.

- Government agencies in charge of tariff regulation in the electric power industry should work harder to eliminate cross-subsidization and switch to market tariff formation mechanisms. State bodies in charge of natural gas tariff regulation should provide adequate regulation of gas retail prices, which will improve the competitiveness of system power generation.

\section{ACKNOWLEDGEMENT}

The work was supported by the Act 211 Government of the Russian Federation, contract № 02.A03.21.0006.

\section{REFERENCES}

[1] Coll-Mayor, D., Paget, M. \& Lightner, E., Future intelligent power grids: analysis of the vision in the European Union and the United States. Energy Policy, 35(4), pp. 2453 2465, 2007.

http://dx.doi.org/10.1016/j.enpol.2006.09.001

[2] Hernandez, J.A., Santamaría, F. \& Trujillo, C.L., Impacts of regulation in the development of distributed generation. The Electricity Journal, 28(7), pp. 83-95, 2015. http://dx.doi.org/10.1016/j.tej.2015.07.002

[3] Novoselova, O.A., Small-scale distributed power generation is a new paradigm in electric powerindustry,VIIIProfessionalForumofRussia'sEnergyTraders,24-25Octoberof2013, [in Russian], available at: http://www.myshared.ru

[4] Electricity Costs of Energy Intensive Industries: An International Comparison, 2015, available at: http://www.ecofys.com/files/files/ecofys-fraunhoferisi-2015-electricitycosts-of-energy-intensive-industries.pdf

[5] Bukowski, M. \& Śniegocki, A., Electricity and Industrial Competitiveness, 2014, available at: https://www.agora-energiewende.de/fileadmin/Projekte/2014/FAE-Strompreise/FAE_Electricity_and_industrial_competitiveness.pdf

[6] Pazderin, A.V., Use and development of electric power systems with small capacity generation, [in Russian], available at: http://www.cigre.ru

[7] Gitelman, L.D. \& Kozhevnikov, M.V., Energy strategies of industrial enterprises. WIT Transactions on Ecology and the Environment, 192, pp. 297-307, 2015. http://dx.doi.org/10.2495/ECO150271

[8] Poullikkas, A., Implementation of distributed generation technologies in isolated power systems. Renewable and Sustainable Energy Reviews, 11(1), pp. 30-56, 2007. http://dx.doi.org/10.1016/j.rser.2006.01.006 
[9] Boscán, L. \& Poudineh, R., Business models for power system flexibility: new actors, new roles, new rules. Future of Utilities Utilities of the Future. How Technological Innovations in Distributed Energy Resources Will Reshape the Electric Power Sector, pp. 363-382, 2016.

[10] Zhao, Z-Y., Zuo, J., Wu, P-H., Yan, H. \& Zillante, G., Competitiveness assessment of the biomass power generation industry in China: A five forces model study. Renewable Energy, 89, pp. 144-153, 2016.

http://dx.doi.org/10.1016/j.renene.2015.12.035

[11] Strategy of Development of the Russian Electric Grid System. Approved by the Russian government's decree of 3 April 2013 N 511-p, [in Russian], The Consultant Plus legal reference system, 2016.

[12] Olaya, Y., Arango-Aramburo, S. \& Larsen, E.R., How capacity mechanisms drive technology choice in powergeneration: The case of Colombia. Renewable and Sustainable Energy Reviews, 56, pp. 563-571, 2016. 